\title{
Przydatność wybranych kwestionariuszy przesiewowych do wykrywania zaburzeń ośrodkowego przetwarzania stuchowego
}

\section{The use of selected questionnaires in the diagnostics of central auditory processing disorders}

\author{
Paulina Krzeszewska ${ }^{1,2}$, Zdzisław M. Kurkowski ${ }^{1,2}$ \\ ${ }^{1}$ Uniwersytet Marii Curie-Skłodowskiej, Zakład Logopedii i Językoznawstwa Stosowanego, Lublin \\ ${ }^{2}$ Instytut Fizjologii i Patologii Słuchu, Światowe Centrum Słuchu, Warszawa/Kajetany
}

Adres autora: Paulina Krzeszewska, Światowe Centrum Słuchu, ul. Mokra 17, Kajetany, 05-830 Nadarzyn, e-mail: p.krzeszewska@ifps.org.pl

\section{Streszczenie}

Zaburzenia ośrodkowego przetwarzania słuchowego (ang. central auditory processing disorders, CAPD) mogą być przyczyną trudności w nauce występujących u dzieci w wieku szkolnym. Nadal nie opracowano odpowiedniej baterii testów diagnozujących CAPD. Jednym z pierwszych etapów procedury diagnostycznej jest przeprowadzenie badań przesiewowych. Niniejsza praca stanowi przegląd zagadnień i badań poświęconych weryfikacji użyteczności trzech kwestionariuszy skriningowych - Dziecięcej Skali Efektywności Przetwarzania Słuchowego (CHAPS), Listy Trudności Słuchowych (FISHER) oraz Skali Zachowań Słuchowych (SAB).

Słowa kluczowe: zaburzenia rozwoju języka $\bullet$ kwestionariusze $\bullet$ zaburzenia percepcji słuchowej $\bullet$ zaburzenia centralnego przetwarzania słuchowego

\begin{abstract}
Central auditory processing disorders (CAPD) may cause difficulties in learing among school children. Although, there has not yet been created an appropriate diagnostic test battery. One of the first steps of the diagnostic procedure in CAPD is conducting screening questionnaires. In this article, the authors overviewed the research on utility verification of three available CAPD questionnaires - the Children's Auditory Performance Scale (CHAPS), the Fisher's Auditory Processing Problems Checklist (FISHER), the Scale of Auditory Behaviors (SAB).
\end{abstract}

Key words: language development disorders $\bullet$ questionnaires $\bullet$ auditory perceptual disorders $\bullet$ central auditory processing disorders

\section{Wprowadzenie}

Amerykańskie Towarzystwo Języka, Mowy i Słuchu (American Speech-Language-Hearing Association, ASHA) opisuje zaburzenia ośrodkowego przetwarzania słuchowego (ang. central auditory processing disorders, CAPD) jako deficyt w zakresie procesów i mechanizmów dotyczących przynajmniej jednej z następujących umiejętności słuchowych:

- lokalizacja i lateralizacja dźwięku,

- słuchowe różnicowanie dźwięków,

- przetwarzanie czasowe dźwięków, w tym: analiza (rozdzielczości) czasowa, maskowanie czasowe, integracja czasowa bodźców, percepcja kolejności bodźców,

- rozumienie sygnału (np. mowy) w obecności sygnału zagłuszającego,

- rozumienie sygnałów zniekształconych [1].
Do rozpoznania zaburzeń CAPD konieczna jest wieloaspektowa ocena zachowań słuchowych. W tym celu przeprowadzane są podstawowe badania audiologiczne, testy behawioralne oraz badania elektrofizjologiczne. Ze względu na to, iż jest to proces czasochłonny i kosztowny, pojawia się potrzeba opracowania możliwie najskuteczniejszego narzędzia przesiewowego. Badania skriningowe wykonuje się w celu wyłonienia populacji, która ma objawy danego zaburzenia. Podczas konferencji Bruton (Consensus Conference on the Diagnosis of Auditory Processing Disorders in School-Aged Children) w 2000 r. klinicyści podkreślili potrzebę modyfikowania już dostępnych kwestionariuszy, testów CAPD oraz tworzenia nowych [2]. 


\section{Wybrane narzędzia badań przesiewowych}

\section{Dziecięca Skala Efektywności Przetwarzania Słuchowego}

The Children's Auditory Performance Scale - CHAPS (Smoski, Brunt, Tanahill, 1998)

Kwestionariusz ten może wypełnić rodzic, nauczyciel lub inny opiekun dziecka. Za pomocą siedmiostopniowej skali od -5 do 1 wypełniający ma określić, jaki poziom trudności słuchowych wykazuje oceniany uczeń w stosunku do rówieśników. Pytania są podzielone na sześć kategorii: [zachowania] w hałasie, ciszy, idealnych warunkach akustycznych, z dodatkowymi bodźcami oraz pamięć słuchowa i zakres uwagi słuchowej. Są to najczęściej wspominane w literaturze przedmiotu wskaźniki oceny procesów przetwarzania słuchowego [3]. Po podsumowaniu i wyliczeniu średniej punktów za normę uznaje się wynik z przedziału od -11 do 36 punktów. Jeśli punktacja znajdzie się w zakresie od -130 do -12 punktów, dziecko kwalifikowane jest do grupy ryzyka i powinno być skierowane na dalszą diagnostykę zaburzeń ośrodkowego przetwarzania słuchowego [4].

CHAPS może być również stosowany jako narzędzie do ewaluacji przebiegu terapii audiologicznej. Po każdym etapie rehabilitacji należy określić, czy nastąpiła u pacjenta poprawa. Najbardziej wiarygodną weryfikacją postępów jest porównanie wyników kwestionariuszy wypełnionych przez terapeutę i opiekuna dziecka. W ten sposób uzyskuje się informację zwrotną na temat zmian w zachowaniach słuchowych dziecka zarówno w gabinecie, jak i w sytuacjach codziennych, np. w domu [5].

Badacze przygotowali swój kwestionariusz na podstawie najczęściej występujących zachowań słuchowych osób ze zdiagnozowanymi zaburzeniami ośrodkowego przetwarzania słuchowego. Grupę 64 dzieci z CAPD, w wieku od 7,1 do 11,8 lat, $\mathrm{z}$ wynikami audiometrii tonalnej, słownej oraz impedancyjnej w normie, zbadano baterią składającą się z czterech testów: testu mowy spondejowej (ang. Staggered Spondaic Word Test, SSW), rozdzielnousznego cyfrowego (ang. Dichotic Digits Test, DDT), testu wzorów o różnej wysokości (ang. Pitch Patterns Test, PPT) oraz testu wyrazów konkurencyjnych (ang. Competing Sentences Test, CST). Diagnozę CAPD stawiano na podstawie wyników poniżej normy z przynajmniej dwóch testów. Dzieci, u których stwierdzono zaburzenia ośrodkowego przetwarzania słuchowego, wykazywały trudności ze słyszeniem oraz rozumieniem w idealnym i cichym otoczeniu akustycznym, podobnie jak w warunkach hałaśliwych i stresujących [6]. Aż 55\% z nich potrzebowało różnego rodzaju specjalistycznego wsparcia, by ukończyć szkołę. W związku z tym autorzy uznali CHAPS za narzędzie odpowiednie do wskazywania dzieci potrzebujących kompleksowej diagnostyki pod kątem CAPD oraz weryfikowania postępów terapii tychże zaburzeń [7].

Bellis uznała CHAPS za jedno z najczęściej stosowanych narzędzi przesiewowych do oceny zdolności słuchowych dzieci [8]. Potwierdziła to Emanuel, badając grupy ankietowanych, którzy mieli odpowiedzieć na pytanie, jaki kwestionariusz stosują do diagnozy CAPD w przypadku swoich podopiecznych. Pierwszą grupę stanowili licencjonowani audiolodzy ze Stanu Maryland, drugą - internauci.
Za najbardziej rozpowszechnione narzędzie obie grupy wskazały kwestionariusz CHAPS [9].

$\mathrm{Z}$ drugiej jednak strony badania pod kierunkiem Drake wykazały brak zależności między wynikami kwestionariusza CHAPS a diagnozą CAPD. Badacze wykorzystali do weryfikacji kwestionariusza baterię testów Bellisa i Ferrego $\mathrm{z}$ następującymi testami behawioralnymi: uzupełnienie fonologiczne (ang. auditory closure), test integracji obuusznej (ang. binaural integration), interakcji obuusznej (ang. binaural interaction), test słuchowy figury i tła (ang. figure ground), test przetwarzania czasowego (ang. temporal processing) i uwagi słuchowej (ang. auditory attention - screening). Wyniki poniżej normy $\mathrm{z}$ dwóch testów w przynajmniej jednym uchu stanowiły kryterium włączające dziecko do grupy ryzyka wystąpienia zaburzeń ośrodkowego przetwarzania słuchowego. Po wykonaniu tych testów wybrano 40 osób, z przedziału wiekowego 8-15 lat. Wyniki jednej połowy wskazywały na normę, wyniki drugiej - na obecność CAPD. Następnie opiekunowie wszystkich uczniów wypełnili kwestionariusz CHAPS. Wśród 20 dzieci z zaburzeniami 15 osiągnęło wynik poniżej normy, $5 \mathrm{w}$ normie. Jednak w grupie bez zaburzeń uzyskano te same rezultaty - 15 osób poniżej normy, 5 w normie. Zespół uznał więc Dziecięcą Skalę Efektywności Przetwarzania Słuchowego za niewystarczające narzędzie przesiewowe do diagnostyki zaburzeń ośrodkowego przetwarzania słuchowego [10].

Podobne wnioski wysnuli australijscy badacze z Uniwersytetów Queensland oraz La Trobe, sprawdzający czułość i specyficzność trzech kwestionariuszy skriningowych do wykrywania zaburzeń centralnego przetwarzania słuchowego, m.in. Dziecięcej Skali Efektywności Przetwarzania Słuchowego. Porównali wyniki CHAPS z wynikami czterech testów behawioralnych CAPD: testu mowy $\mathrm{z}$ filtrem dolnoprzepustowym (ang. Low-Pass Filtered Speech, LPFS), rozdzielnousznego testu cyfrowego (ang. Two-Pair Dichotic Digits, DD), testu konkurencyjnych wyrazów (ang. Competing Sentences, CS) i testu wzorców częstotliwości (ang. Frequency Patterns, FP). Po zbadaniu 71 chłopców i 33 dziewczą w wieku 6,9-14,3 lat wykazano korelacje między wynikami kwestionariusza CHAPS a pojedynczymi wynikami każdego z testów behawioralnych - od słabej (współczynnik $r$ Pearsona $=0,22$, przy poziomie istotności $<0,05$ ) do średniej (współczynnik r Pearsona $=0,47$, przy poziomie istotności $<0,01$ ). Dodatkowo pokazano, że wyniki wszystkich trzech weryfikowanych kwestionariuszy skriningowych (CHAPS, SIFTER, TAPS-R) stanowią niepewną podstawę prognozy wyników - zarówno poszczególnych testów diagnostycznych CAPD, jak i całkowitego ryzyka obecności zaburzeń ośrodkowego przetwarzania słuchowego (żaden $\mathrm{z}$ nich nie uzyskał 5\% poziomu istotności). Dlatego też badacze uznali, że wynik Dziecięcej Skali Efektywności Przetwarzania Słuchowego poniżej normy nie powinien determinować podjęcia dalszej diagnostyki pod kątem CAPD [11].

\section{Lista Trudności Słuchowych Fishera}

\section{The Fisher's Auditory Processing Problems Checklist - FISHER (Fisher, 1985)}

Podobnie jak w kwestionariuszu CHAPS Listę Trudności Słuchowych Fishera wypełnia rodzic lub nauczyciel. Składa 
się ona z 25 stwierdzeń, dotyczących trudności w zakresie 13 umiejętności związanych z przetwarzaniem słuchowym, tj. ostrości, uwagi, zakresu uwagi, selektywności figury i tła, dyskryminacji, pamięci krótkotrwałej, pamięci długotrwałej, pamięci sekwencyjnej, rozumienia, obecności wady mowy, integracji słuchowo-wzrokowej, motywacji, wyników w nauce [12]. Część pytań odpowiada zaleceniom ASHA dotyczącym istotnych zachowań ocenianych w kwestionariuszach przesiewowych CAPD, z 1996 i 2005 r. [13].

Wynikiem kwestionariusza jest pomnożona razy cztery liczba stwierdzeń niezaznaczonych. Nieopublikowane badania Fishera wskazywały wartość graniczną, wynoszącą $72 \%$. Dziecko, które uzyska taki bądź niższy wynik, powinno być skierowane na dalszą diagnostykę pod kątem zaburzeń ośrodkowego przetwarzania słuchowego [14]. Proponuje się też wykorzystanie Listy Trudności Słuchowych Fishera do badań przesiewowych słuchu obwodowego u dzieci [15].

Smoski, Brunt i Tannahill (1992) zarzucają Liście Fishera zbyt duże poświęcenie uwagi charakterystyce dziecka, a za małe zachowaniom słuchowym - istotnym dla oceny procesów ośrodkowego przetwarzania słuchowego. Krytykują także pominięcie wpływu warunków akustycznych, w jakich dziecko się znajduje, na ewaluację zdolności słuchowych [14]. Do tej opinii przychyliła się Emanuel, określając kwestionariusz, jako „ograniczony” dla potrzeb diagnostyki CAPD, w porównaniu chociażby z CHAPS-em [9]. Robiąc przegląd stosowanych narzędzi przesiewowych zaburzeń centralnego przetwarzania słuchowego, także Roeser i Clark skrytykowały Listę Fishera. Według informacji przez nie zebranych, nie tylko klasyfikacja wszystkich punktów listy odznacza się słabą specyficznością, ale cały kwestionariusz nie spełnia wymaganych norm. Podkreśliły też, że nikt dotąd nie podjął się walidacji narzędzia [16].

Pomimo powyższych stwierdzeń przeprowadzone badania (Smoski, Brunt i Tannahill 1992) nad użytecznością Listy Słuchowych Trudności wykazały zależność między wynikiem kwestionariusza a diagnozą CAPD, opartą na diagnostycznej baterii testów Modelu Buffalo. Opiekunowie dzieci otrzymali do wypełnienia 57 kwestionariuszy, z czego 17 odrzucono ze względu na niewłaściwe wypełnienie, diagnozę ADHD u podopiecznego lub osiagnnięcie wyniku powyżej $72 \%$. Do badania zakwalifikowano 23 chłopców i 17 dziewcząt, w wieku 6-13 lat. U wszystkich uczestników zdiagnozowano prawidłowy słuch obwodowy. Wyniki kwestionariusza wahały się między 32\% a $72 \%$, gdzie średni wynik wyniósł $54 \%$. Badanie wykazało, że 75\% dzieci przejawiało tolerancję zanikania (zacierania) śladów pamięciowych, 70\% - deficyt dekodowania, 53,5\% - deficyt organizacji, a 30\% - deficyt integracji. Analiza wskazuje na istotną statystycznie zależność deficytów i wyników diagnozy zaburzeń ośrodkowego przetwarzania słuchowego. Do oceny (C)APD wykorzystano trzy testy behawioralne: test mowy spondejowej (ang. Staggered Spondaic Word Test, SSW), test syntezy fonematycznej (ang. Phonemic Synthesis Test, PST) oraz test rozumienia mowy w szumie (ang. W-22 Speech-In-Noise, W-22 SIN). Statystycznie wyniki kwestionariusza istotnie korelowały tylko z wynikami testów mowy spondejowej. Wyniki badań, które przeprowadziła Stecker (1998), nieco się różniły od powyższych. W swojej grupie badawczej odnotowała dekodowanie na poziomie $49 \%$, tolerancję zanikania (zacierania) śladów pamięciowych na poziomie $43 \%$, organizację - 18\%, a integrację - u 8\% dzieci z (C)APD [14].

\section{Skala Zachowań Słuchowych}

The Scale of Auditory Behaviors - SAB (Conlin 2006; Schow 2006; Summers 2003)

Najkrótszym kwestionariuszem sprawdzającym możliwości przetwarzania słuchowego dzieci jest Skala Zachowań Słuchowych (ang. The Scale of Auditory Behaviors, SAB). Zawartych w nim 12 pytań odwołuje się do zaleceń z konferencji Bruton (2000) oraz Chermaka, Sommersa i Seikela (1998) [6]. Wypełnia go rodzic lub nauczyciel, określając częstość występowania zaburzeń zachowań słuchowych u dziecka. Przy każdym pytaniu stawia się ocenę, zależnie od częstotliwości występowania danej trudności: 1 bardzo często, 2 - często, 3 - czasami, 4 - rzadko, 5 - nigdy. Suma punktów daje wynik w przedziale od 12 do 60 punktów, przy czym za średnią dla wieku 8-12 lat podano 46 punktów [19]. Za wynik sugerujący obecność lub ryzyko wystąpienia CAPD uznano mniej niż 30 punktów [6].

Skala Zachowań Słuchowych stanowi część baterii diagnostycznej MAPA. Zestaw testów został przygotowany przez Dominitza, Schowa i współautorów (2000) na potrzeby oceny słuchowego przetwarzania u dzieci w wieku szkolnym. Znormalizowano ją na podstawie badań 119 dzieci w wieku 8-11 lat.

Czułość i specyficzność kwestionariusza sprawdziła grupa badaczy z Portugalii. Przystosowawszy SAB do języka portugalskiego, zbadano 51 dzieci bez zdiagnozowanych zaburzeń ośrodkowego przetwarzania słuchowego. Wykonane zostały: audiometria tonalna, impedancyjna, słowna oraz 8 testów behawioralnych. Porównano wyniki kwestionariusza $\mathrm{z}$ wynikami zestawu testów behawioralnych, do których należały: test lokalizacji dźwięku (ang. Sound Localization, SL), test sekwencyjnej pamięci werbalnej (ang. Verbal Sequential Memory, VSM), test sekwencyjnej pamięci niewerbalnej (ang. Nonverbal Sequencing Memo$r y$, NSM), test rozumienia mowy w szumie (ang. Speech In Noise, SIN), test rozdzielnouszny cyfrowy (ang. Dichotic Digits, DDs), test rozdzielnouszny cyfrowy ze wzorcami harmonicznymi (ang. Harmonic Pattern with Dichotic Digits, HPDDs), test wzorców czasu trwania (ang. Duration Pattern Recognition, DPR), test wykrywania przerw w szumie (ang. Gaps-In-Noise, GIN). Pierwsze trzy próby wykonywano $\mathrm{w}$ wolnym polu, a pozostałe $\mathrm{z}$ użyciem przenośnego audiometru przesiewowego. Wynik poniżej średniej (<46) uzyskało 18 dzieci, z czego 17 wykazało trudności w przynajmniej jednym teście behawioralnym. U 3 dzieci odnotowano wynik niższy niż 35 punktów, co było spójne z niskimi wynikami minimum 2 testów przetwarzania słuchowego. Spośród wszystkich testów behawioralnych, jedynie test wykrywania przerw w szumie (GIN) nie wskazywał na związek z wynikami kwestionariusza. Jednak pomiędzy wynikami Skali Zachowań Słuchowych oraz większością testów behawioralnych zachodziła statystycznie istotna korelacja [17].

Rozbieżność w wynikach SAB i GIN również odnotowano w badaniach egipskich dzieci. Z ramienia Uniwersytetu Ain Shams zbadano 60 dzieci zdrowych i 25 dzieci 
z zaburzeniami ośrodkowego przetwarzania słuchowego. Dostosowawszy kwestionariusz do potrzeb języka arabskiego, badacze przekazali go do wypełnienia rodzicom badanych. Następnie użyto do badań baterii składającej się z następujących testów behawioralnych: test rozumienia mowy w szumie (ang. Speech In Noise, SIN), rozdzielnouszny cyfrowy (ang. Dichotic Digits Test, DDT), różnicowania wysokości (ang. Pitch Patterns Test, PPT) oraz testy wystandaryzowane $\mathrm{z}$ udziałem egipskich dzieci - test wykrywania przerw w szumie (ang. Gaps In Noise, GIN) i test syntezy słuchowej (ang. Auditory Fusion Test, AFT). Dwa ostatnie testy były skorelowane ze sobą, ale nie z wynikami Skali Zachowań Słuchowych. Badacz tę różnicę uzasadnił odniesieniem kwestionariusza do wszystkich zdolności przetwarzania słuchowego, podczas gdy GIN oraz AFT skupiają się na kontroli przetwarzania czasowego. Niemniej wyniki testów dzieci z CAPD były w tych testach istotnie niższe [18].

\section{Wnioski}

Wczesne wykrycie zaburzeń ośrodkowego przetwarzania słuchowego jest niezbędne do podjęcia wczesnej terapii, której skuteczność może być większa. Z kolei efekty prowadzonej rehabilitacji mają wpływ na funkcjonowanie komunikacyjne, edukacyjne i społeczne jednostki [20]. Ważne zatem wydaje się opracowanie polskiej baterii narzędzi diagnostycznych, do których powinien należeć także kwestionariusz przesiewowy. Zanim jednak podejmie się decyzję o wykorzystaniu amerykańskich kwestionariuszy takich, jak powyższe - niezbędne jest przeprowadzenie procesu ich adaptacji i walidacji.

Artykut powstat $w$ związu $z$ realizacja projektu „Zintegrowany system narzędzi do diagnostyki i telerehabilitacji schorzeń narzadów zmysłów (słuchu, wzroku, mowy, równowagi, smaku, powonienia)" wspólfinansowanego przez Narodowe Centrum Badań $i$ Rozwoju w ramach Programu STRATEGMED.

\section{Piśmiennictwo:}

1. ASHA. Central Auditory Processing: current status of research and implications for clinical practice. Am Journal of Audiol, 1996; 5: 41-54.

2. Jerger J, Musiek F. Report of the Consensus conference on the diagnosis of Auditory Processing Disorders in school-aged children. J Am Acad Audiol, 2000; 11(9): 467-74.

3. Smoski WJ, Brunt MA, Tannahill JC. Listening characteristics of children with Central Auditory Processing Disorders. Language, Speech, and Hearing Services in Schools, 1998; 23: $145-52$.

4. Smoski W. Use of CHAPPS in a children's audiology clinic. Ear Hear, 1990; 11: 53-56.

5. Florida Department of Education. Technical Assistance Paper - Auditory Processing Disorders; 2001.

6. Schow R, Seikel A. Screening for (Central) Auditory Processing Disorder. W: Musiek F, Chermak G. Handbook of Central Auditory Processing Disorder. Vol. 1: Auditory Neuroscience and Diagnosis. San Diego: Plural Publishing; 2007, s. 137-59.

7. Keith R, Diagnosing (Central) Auditory Processing Disorders in Children. W: Roeser R, Valente M, Hosford-Dunn H. Audiology. Diagnosis. New York: Thieme Medical Publishers; 2007, s. 343.

8. Bellis TJ. Audiologic behavioral assessement of APD. W: Parthasarathy T. An introduction to Auditory Processing Disorders in children. New Jersey: Lawrence Erlbaum Associates; 2006, s. 63-80.

9. Emanuel D. The Auditory Processing Battery: Survey of common practices. J Am Acad Audiol, 2002; 13: 96-100.

10. Drake M, Brager M, Leyendecker J, Preston M, Shorten E, Stoos R i wsp. Comparison of the CHAPPS screening tool and APD diagnosis. Praca zaprezentowana na Konwencie ASHA, Miami Beach, 2006; http://convention.asha.org/2006/handouts/855_0427Drake_Mary_072995_120106033139.pdf
11. Wilson W, Jackson A, Pender A, Rose C, Wilson J, Heine C i wsp. The CHAPS, SIFTER, and TAPS-R as predictors of (C) AP skills and (C)APD. J Speech Lang Hear Res, 2011; 54: 278-91.

12. Pavlick ML, Zalewski TR, González JE, Duncan MK. A (C) APD screening instrument for the Buffalo Model Diagnostic Test Battery. Journal of Educational Audiology, 2010; 16: 4-10.

13. Schow RL, Seikel JA. Screening for (Central) Auditory Processing Disorder. W: Musiek FE, Chermak GD, Handbook of (Central) Auditory Processing Disorders. Vol. 1: Auditory Neuroscience and Diagnosis. San Diego CA: Plural Publishing Inc, 2007; s. 137-55.

14. Strange AK, Zalewski TR, Waibel-Duncan MK. Exploring the usefulness of Fisher's Auditory Problems Checklist as a screening tool in relationship to the Buffalo Model Diagnostic Central Auditory Processing Test Battery. Journal of Educational Audiology, 2009; 15: 44-50.

15. Johnson C. Assessement of the educational effects of hearing loss. W: Johnson C, Seaton J. Educational Audiology Handbook. Nowy Jork: Delmar, 2012; s. 124-26.

16. Roeser R, Clarc J. Auditory disorders in school children: The law, identification, remediation. W: Roeser R, Downs M. Auditory Disorders in School Children: The Law, Identification, Remediation. Nowy Jork: Thieme Medical Publishers, 2004; s. 96-128.

17. Nunes CL, Pereira LD, Carvalho GS. Scale of Auditory Behaviors and auditory behavior tests for auditory processing assessment in Portuguese children. CodAS, 2013; 25(3): 209-15.

18. Gad NH. Gaps-In-Noise Test versus Auditory Fusion Test in diagnosis of Auditory Temporal Processing Disorder. Ain Shams University; 2009.

19. Summers SA. Factor structure, correlations, and mean data on form A of the Beta III Version of Multiple Auditory Processing Assessment (MAPA). Idaho State University; 2003.

20. Chermak GD. Central testing. W: Gerber SE. The Handbook of Pediatric Audiology. Washington: Gallaudet University Press, 1996; s. 206-53. 